\title{
Oxygen and Hydroxyl Species Induce Multiple Reaction Pathways for the Partial Oxidation of Allyl Alcohol on Gold
}

\author{
Gregory M. Mullen, ${ }^{\dagger}$ Liang Zhang, ${ }^{\ddagger}$ Edward J. Evans, Jr., ${ }^{\ddagger}$ Ting Yan, ${ }^{\ddagger}$ Graeme Henkelman, \\ and C. Buddie Mullins ${ }^{*},+$,
}

\begin{abstract}
${ }^{\dagger}$ McKetta Department of Chemical Engineering and Department of Chemistry, and ${ }^{\ddagger}$ Center for Nano and Molecular Science and Technology, Texas Materials Institute, and Center for Electrochemistry, University of Texas at Austin, Austin, Texas 78712-0231, United States
\end{abstract}

\section{Supporting Information}

\begin{abstract}
Partial oxidation of alcohols is a topic of great interest in the field of gold catalysis. In this work, we provide evidence that the partial oxidation of allyl alcohol to its corresponding aldehyde, acrolein, over oxygen-precovered gold surfaces occurs via multiple reaction pathways. Utilizing temperature-programmed desorption (TPD) with isotopically labeled water and oxygen species, reactive molecular beam scattering, and density functional theory (DFT) calculations, we demonstrate that the reaction mechanism for allyl alcohol oxidation is influenced by the relative proportions of atomic oxygen and hydroxyl species on the gold surface. Both atomic oxygen and hydroxyl species are shown to be active for allyl alcohol oxidation, but each displays a different pathway of oxidation, as indicated by TPD measurements and DFT calculations. The hydroxyl hydrogen of allyl alcohol is readily abstracted by either oxygen adatoms or adsorbed hydroxyl species on the gold surface to generate a surface-bound allyloxide intermediate, which then undergoes $\alpha$-dehydrogenation via

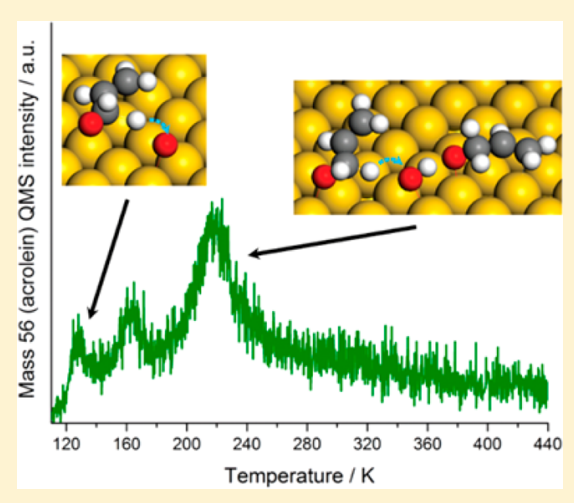
interaction with an oxygen adatom or surface hydroxyl species to generate acrolein. Mediation of a second allyloxide with the hydroxyl species lowers the activation barrier for the $\alpha$-dehydrogenation process. A third pathway exists in which two hydroxyl species recombine to generate water and an oxygen adatom, which subsequently dehydrogenates allyloxide. This work may aid in the understanding of oxidative catalysis over gold and the effect of water therein.
\end{abstract}

\section{INTRODUCTION}

Gold was long thought to be an inert material with no catalytic use, but in 1973, Bond et al. showed that olefin hydrogenation could be facilitated by gold catalysts. ${ }^{1}$ In the mid-1980s, gold catalysts were demonstrated to display high activity for the $\mathrm{CO}$ oxidation reaction by Haruta et al. ${ }^{2}$ and for hydrochlorination of ethylene by Hutchings. ${ }^{3}$ These discoveries led to an explosion of interest in the field of gold catalysis. Gold has been demonstrated to catalyze both oxidation and hydrogenation reactions, displaying exceptional activity and selectivity for a host of processes of catalytic interest at low temperatures. $^{4-7}$ Studies of model gold surfaces have guided catalyst development and enhanced the fundamental understanding of gold-adsorbate interactions. ${ }^{8-15}$

Several studies have shown that gold displays exceptional activity and selectivity for catalytic partial oxidation reactions of alcohols, ${ }^{16-19}$ a class of transformation of interest to several industries including pharmaceuticals, cosmetics, and agrochemicals. Current practices for carrying out such reactions utilize hazardous and expensive metal oxides as stoichiometric reactants. A "green" alternative for carrying out such processes utilizing a catalytic material is desirable. Catalysts composed of gold, ${ }^{16,18,19}$ palladium, ${ }^{20}$ and gold-palladium bimetallic mixtures $^{21}$ have been shown to display activity for the partial oxidation of a number of alcohols, demonstrating high selectivity toward the corresponding aldehydes. Despite the breadth of investigation on the subject, the reaction mechanisms and active sites for oxidation of alcohols over gold catalysts remain topics of debate. Model studies performed on single-crystal surfaces in ultrahigh vacuum (UHV) have helped elucidate the mechanisms for partial oxidation of many simple alcohols over gold surfaces. ${ }^{22-28}$ However, little investigation into the partial oxidation of alcohol species with multiple functional groups has been carried out. ${ }^{25,29}$ Furthermore, studies have shown that on gold surfaces oxidation mechanisms for simple alcohols vary as chain length is increased. ${ }^{24}$ Accordingly, the presence of multiple functional groups may also prove to influence oxidative reaction pathways over gold surfaces.

Corma et al. have shown that allylic alcohols do not display the same trends in reactivity as simple alcohols for catalytic partial oxidation processes carried out over palladium-gold systems. ${ }^{30}$ These catalysts induce isomerization, hydrogenation, and polymerization pathways in addition to catalyzing the partial oxidation reaction. ${ }^{30}$ Model palladium surfaces have been shown to catalyze the partial oxidation of allyl alcohol to acrolein, the corresponding aldehyde, in addition to inducing

Received: March 7, 2014

Published: April 6, 2014 
parallel reaction processes. ${ }^{31,32}$ The side reactions observed over palladium-gold catalysts ${ }^{30}$ and model palladium surfaces $^{31,32}$ limit the selectivity toward the partial oxidation pathway. In contrast, gold catalysts supported on nanoparticulate ceria have demonstrated high activity and selectivity for the partial oxidation of allylic alcohols. ${ }^{30,33}$ It is of interest to understand the fundamental reactive processes that occur between allylic alcohols and oxygen on the gold surface.

Some studies have investigated the oxidation of allylic alcohols over the oxygen-covered $\mathrm{Au}(111)$ surface. $^{25,29}$ In an UHV study, Deng et al. showed that the $\mathrm{Au}(111)$ surface precovered with oxygen adatoms by exposure to ozone induced the partial oxidation of allyl alcohol to acrolein in the subsequent temperature-programmed desorption (TPD) spectrum at $255 \mathrm{~K}$ in addition to producing several other oxidation products $\left(\mathrm{CO}_{2}\right.$, acrylic acid, and carbon suboxide $){ }^{29}$ Based on analogy to TPD studies of isotopically labeled propene on $\mathrm{O} /$ $\mathrm{Au}(111)$, which displayed a similar product distribution, they proposed a mechanism for this reaction that proceeds through a surface-bound allyloxide intermediate. ${ }^{29} \mathrm{Liu}$ et al. showed that cyclohexanol (a saturated alcohol) and 2-cyclohexen-1-ol (an allylic alcohol) exhibit differences in reactivity on $\mathrm{O} / \mathrm{Au}(111){ }^{25}$ Both species were oxidized to yield their corresponding ketones and $\mathrm{CO}_{2}$, but 2-cyclohexen-1-ol also underwent secondary oxidation pathways, resulting in the production of 2-cyclohexene-1,4-dione and phenol. ${ }^{25}$ The observation of additional pathways for 2-cyclohexen-1-ol was attributed to the higher relative acidity of the allylic $\mathrm{C}-\mathrm{H}$ bonds in 2-cyclohexen-1-ol vs $\mathrm{C}-\mathrm{H}$ bonds in cyclohexanol. ${ }^{25}$ These works present interesting insights into the oxidation of allylic alcohols over gold surfaces.

Studies have explored the effects of water and hydroxyl species on the catalytic activity of gold surfaces toward a host of reactions. $^{34,35}$ Water has been shown to significantly enhance the activity of gold catalysts for $\mathrm{CO}$ oxidation. ${ }^{36-39}$ The mechanistic reason for this enhancement remains a topic of debate. Some studies have argued that water aids in the activation of molecular oxygen, ${ }^{48,41}$ while others suggest that it is associated with the decomposition of reactive intermediates on the gold surface. ${ }^{42}$ Yet another possible explanation is provided by Ide et al. in a review of the role of hydroxyl species in gold catalysis. ${ }^{35}$ The authors provide interesting evidence linking $\mathrm{CO}$ oxidation experiments carried out in the vapor phase to experiments performed in the liquid phase in both classical catalytic and electrocatalytic systems. Their conclusions suggest that hydroxyl species on the gold surface are responsible for oxidizing $\mathrm{CO}$, while $\mathrm{O}_{2}$ acts to scavenge electrons from the surface and regenerate hydroxyl species.

Water has also been shown to affect the activity of gold surfaces for other reactions. Propene epoxidation ${ }^{43-45}$ and the reduction of nitric oxide with propene ${ }^{46}$ have been shown to be enhanced by the presence of water when carried out over gold catalysts. Additionally, water plays an important role in the selective oxidation of alcohols on gold catalysts. ${ }^{35,47}$ Water is a component in every system for the selective oxidation of alcohols to aldehydes, as a product of the reaction at the very least, but often as a solvent as well. ${ }^{16,17,48}$ Differences have been observed for alcohol oxidation carried out in water versus in the absence of solvent. ${ }^{17}$ Furthermore, changing the $\mathrm{pH}$ of the solution has been shown to significantly affect the oxidation activity for various alcohol species over gold catalysts, with the reaction occurring more readily in basic solutions. ${ }^{35,48}$ When carrying out partial oxidation of alcohols in alkaline media, production of the corresponding carboxylic acid dominates rather than that of the aldehyde, but this process has been suggested to first proceed through the production of the corresponding aldehyde. ${ }^{17}$ Evidence has been provided to suggest that production of the aldehyde is the rate-limiting step of the partial oxidation process to generate carboxylic acids. ${ }^{49}$ The incorporation of base in the reactant solution, therefore, appears to increase the rate of alcohol oxidation to the resulting aldehyde. An increase in the presence of surface hydroxyl species when in basic solutions may be responsible for this enhancement in partial oxidation activity. Several studies have supported this conclusion, as summarized in the excellent review by Ide et al. ${ }^{35}$ Of particular interest is the observation that the effect of gold particle size on activity for glycerol and $\mathrm{CO}$ oxidation reactions is far less significant for systems in basic aqueous media than in neutral, acidic, or vapor-phase conditions. ${ }^{50}$ In fact, even bulk gold powder has been shown to display activity for these reactions in basic solutions. ${ }^{50}$

Here we report on the systematic study of allyl alcohol oxidation over the $\mathrm{Au}(111)$ surface precovered with various exposures of oxygen and hydroxyl species. We utilize TPD with isotopically labeled water $\left(\mathrm{D}_{2} \mathrm{O}\right)$ and oxygen $\left({ }^{18} \mathrm{O}\right)$, reactive molecular beam scattering (RMBS), and density functional theory (DFT) methods to elucidate the mechanistic details of the selective oxidation of allyl alcohol to acrolein. This reaction can occur through multiple pathways, proceeding via both reaction-limited and desorption-limited kinetic processes. The choice of pathway is dictated by the arrangement of oxygen adatoms, hydroxyl species, and allyloxide intermediates on the gold surface. Our results suggest that both oxygen adatoms and hydroxyl species can oxidize allyl alcohol to acrolein, depending on the relative proportions of surface species. These observations may aid in the general mechanistic understanding of oxidative alcohol catalysis and enhance the fundamental understanding of oxidation reactions over gold surfaces.

\section{EXPERIMENTAL AND COMPUTATIONAL METHODS}

2.1. UHV Experiments. All experiments in this study were performed in an UHV chamber that has been described in detail previously. ${ }^{51} \mathrm{~A}$ thin $\mathrm{Au}(111)$ single-crystal sample, cut into a circular disk $\sim 11 \mathrm{~mm}$ in diameter and $1.5 \mathrm{~mm}$ thick, is mounted to a tantalum plate that can be resistively heated to $900 \mathrm{~K}$ via a DC power supply regulated by a proportional-integral-differential controller. The gold sample is also in thermal contact with a liquid nitrogen reservoir for cooling to a minimum temperature of $77 \mathrm{~K}$. The sample temperature was monitored with a K-type thermocouple spot-welded to the tantalum plate. Prior to each experiment, the gold surface was cleaned by exposure to atomic oxygen at $77 \mathrm{~K}$, followed by annealing to $700 \mathrm{~K}$ unless otherwise specified. Cleanliness was routinely verified by Auger electron spectrometry (AES). Periodically, the surface was sputtered by $\mathrm{Ar}^{+}$ion bombardment at room temperature to remove impurities, followed by annealing to $800 \mathrm{~K}$ for $10 \mathrm{~min}$ to restore the (111) structure.

Reactants were delivered to the sample via a supersonic molecular beam dosing apparatus consisting of four differentially pumped subchambers. Analyses were carried out in a scattering chamber (base pressure of less than $1 \times 10^{-10}$ Torr) equipped for quadrupole mass spectrometry (QMS), AES, and low-energy electron diffraction.

TPD spectra were obtained by heating the $\mathrm{Au}(111)$ sample at a rate of $2 \mathrm{~K} / \mathrm{s}$ while monitoring desorption of various species via QMS. For oxidation experiments, oxygen adatoms were dosed onto the sample first, followed by allyl alcohol. Isotopic oxygen was employed in these experiments to observe the production of water in TPD spectra without interference from $\mathrm{H}_{2}{ }^{16} \mathrm{O}$ displaced from the chamber walls by allyl alcohol (see Supporting Information for further discussion). We populated the $\mathrm{Au}(111)$ surface with ${ }^{18} \mathrm{O}$ and monitored $\mathrm{m} / z=20$ $\left(\mathrm{H}_{2}{ }^{18} \mathrm{O}\right)$, which was not affected by allyl alcohol desorption in the 
chamber. Additionally, the use of ${ }^{18} \mathrm{O}$ allowed us to determine whether oxygen associated with the surface was exchanged with oxygen in allyl alcohol or incorporated into the resulting products.

Oxygen adatoms were dosed onto the gold sample via a radio frequency (RF)-powered plasma-jet source using a gas mixture of $8 \%$ (v/v) $\mathrm{O}_{2}$ in argon. ${ }^{52,53}$ Oxygen surface coverages were estimated by AES following a method employed in a previous study. ${ }^{38}$ All reactant species were dosed onto the sample through the same nozzle to promote coincident exposure, but the RF power was only engaged while dosing the atomic oxygen. Deionized water was used for TPD experiments employing $\mathrm{H}_{2} \mathrm{O}$. Allyl alcohol (ACROS, 99\%), $\mathrm{D}_{2} \mathrm{O}$ (Spectra, 99.9\%), ${ }^{16} \mathrm{O}_{2}$ (Matheson Trigas, 99.99\%), ${ }^{18} \mathrm{O}_{2}$ (Isotec, 99\%), and $\operatorname{Ar}$ (Matheson Trigas, 99.9\%) were used as received, without further purification.

RMBS spectra were obtained by monitoring product and reactant species via QMS while impinging allyl alcohol onto the $\mathrm{O} / \mathrm{Au}(111)$ surface held at constant temperature. Atomic oxygen was dosed onto the $\mathrm{Au}(111)$ surface at $77 \mathrm{~K}$. The surface was then ramped to the specified temperature in vacuum prior to impingement of pure allyl alcohol. Allyl alcohol was impinged first onto an inert flag held in front of the gold sample to obtain baseline signals for each spectrum and then impinged onto the sample itself to observe product generation signals. Under these conditions, we estimate the allyl alcohol translational energy to be approximately $0.1 \mathrm{eV}$ and that virtually every allyl alcohol molecule is adsorbed to both the clean and adsorbate-covered surfaces. ${ }^{54-56}$

2.2. DFT Calculations. Calculations were performed with the Vienna ab initio simulation package. ${ }^{57-60}$ The interaction between the ionic core and the valence electrons was described by the projectoraugmented wave method, ${ }^{61}$ and the valence electrons were described with a plane-wave basis up to an energy cutoff of $280 \mathrm{eV}^{62,63}$ The exchange correlation contribution to the total energy functional was determined using the PBE generalized gradient approximation functional. ${ }^{64}$ Corrections for van der Waals interactions were made using the optB86b-dvW density functional as implemented by Klimeš et al. ${ }^{65}$ The location and energy of the transition states were calculated with the climbing-image nudged elastic band method. ${ }^{6,67}$ Spin polarization was tested and applied when necessary. The gold surface was modeled as a $3 \times 3 \mathrm{Au}(111)$ slab with four atomic layers and $14 \AA$ of vacuum. The Brillouin zone was sampled using a $4 \times 4 \times 1$ Monkhorst-Pack $k$-point mesh. ${ }^{68}$ The convergence criteria for the electronic structure and the atomic geometry were $10^{-4} \mathrm{eV}$ and 0.01 $\mathrm{eV} / \AA ̊$, respectively.

\section{RESULTS AND DISCUSSION}

3.1. Allyl Alcohol Desorption from the Clean Au(111) Surface. TPD spectra were taken for allyl alcohol desorption from the clean $\mathrm{Au}(111)$ surface for coverages ranging from 0.5 to 7.7 monolayers (ML). These spectra, depicted in Figure 1, were obtained by monitoring $\mathrm{m} / z=57$ (the primary mass fragment for allyl alcohol) via QMS. The desorption spectra displayed three features, which we label $\alpha_{1}, \alpha_{2}$, and $\beta$. The $\beta$ feature displayed a peak at $195 \mathrm{~K}$. This feature was populated first and saturated before the $\alpha_{1}$ and $\alpha_{2}$ features began to appear. First-order desorption behavior was observed for this feature, with a desorption energy estimated to be $50.1 \mathrm{~kJ} / \mathrm{mol}$ by Redhead analysis. ${ }^{69}$ We attribute the $\beta$ feature to desorption of the allyl alcohol monolayer interacting directly with the $\mathrm{Au}(111)$ surface.

The $\alpha_{2}$ feature displayed a peak at $167 \mathrm{~K}$. This feature began to populate after the $\beta$ feature had saturated and also displayed first-order desorption kinetics. The desorption energy for this feature was estimated to be $42.7 \mathrm{~kJ} / \mathrm{mol}$ by Redhead analysis. ${ }^{69}$ The $\alpha_{2}$ peak saturated before the $\alpha_{1}$ feature began to populate. The desorption of alcohol species from a number of different surfaces has demonstrated features similar to $\alpha_{2}$ in the allyl alcohol TPD spectrum. ${ }^{24,70-73}$ Brown et al. observed similar

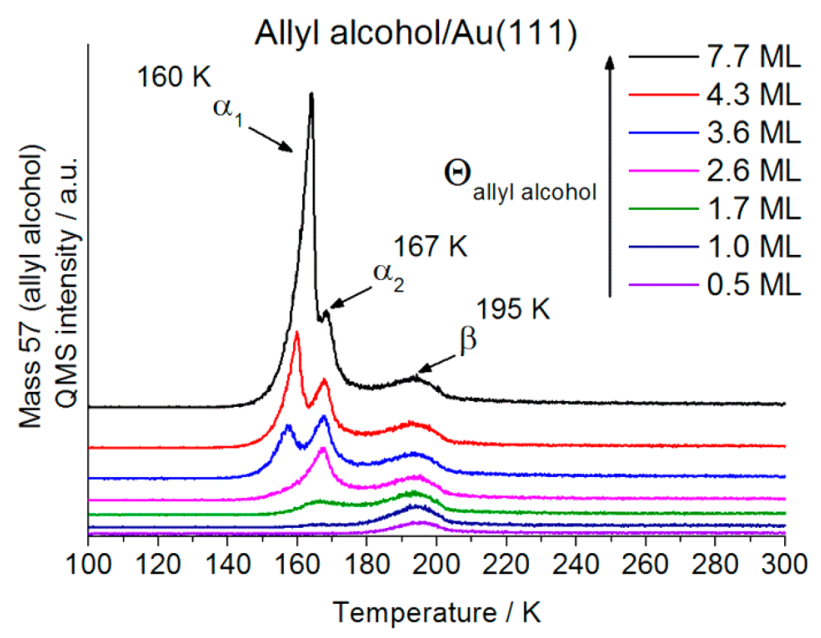

Figure 1. TPD spectra for allyl alcohol $(m / z=57)$ desorption from $\mathrm{Au}(111)$. Allyl alcohol was adsorbed on the $\mathrm{Au}(111)$ surface at a sample temperature of $77 \mathrm{~K}$.

behavior for allyl alcohol TPD from the $\mathrm{Rh}(111)$ surface; $^{73}$ however, the reasons for such behavior were not discussed in that work. Ehlers et al. studied the interactions of methanol with the $\mathrm{Pt}(111)$ surface via IR spectroscopy and observed that three distinct layers were formed on this surface. ${ }^{71}$ The methanol monolayer interacted strongly with the surface and did not undergo hydrogen-bonding interactions. The multilayers of methanol, on the other hand, did hydrogen bond, as evidenced by the width and position of the $\mathrm{O}-\mathrm{H}$ stretch. At the dosing temperature of $90 \mathrm{~K}$, the methanol multilayers were amorphous. A significant portion of the multilayer methanol underwent a phase transition to generate an $\alpha$-ice phase upon annealing the surface, while some of the multilayer remained amorphous due to stronger interaction with the surface or with the methanol monolayer. Similar observations were made in the study of ethanol on highly ordered pyrolytic graphite, ${ }^{72}$ which displayed a TPD spectrum very similar to that we have observed for allyl alcohol desorption from the $\mathrm{Au}(111)$ surface in this study, suggesting that the formation of an amorphous second layer interacting with the monolayer or weakly with the surface may be a general phenomenon displayed in a number of alcohol/surface interactions. Additionally, both methanol ${ }^{70}$ and 2-butanol ${ }^{24}$ have been shown to display similar features for desorption from the $\mathrm{Au}(111)$ surface, in further support of this phenomenon.

The $\alpha_{1}$ feature displayed a peak at $\sim 160 \mathrm{~K}$. This feature appeared after the $\alpha_{2}$ feature had saturated and grew indefinitely as allyl alcohol coverage was increased, displaying zero-order desorption kinetics. These characteristics are consistent with desorption of condensed phase multilayers physisorbed on top of the $\alpha_{2}$ species.

No decomposition, coupling, or isomerization products were detected during allyl alcohol TPD from the $\mathrm{Au}(111)$ surface. AES taken after allyl alcohol desorption tests did not detect the presence of decomposition products (carbon and oxygen) on the $\mathrm{Au}(111)$ surface. Furthermore, TPD spectra of allyl alcohol desorption from the clean $\mathrm{Au}(111)$ surface taken repeatedly without cleaning the surface in between experiments were highly reproducible, suggesting that the surface was unchanged before and after each experiment. These observations suggest that allyl alcohol did not react during TPD experiments on the clean $\mathrm{Au}(111)$ surface. 
3.2. Acrolein Desorption from the Clean $\mathrm{Au}(111)$ Surface. TPD spectra were taken for acrolein desorption, monitored by $m / z=56$ (the parent mass of acrolein), from the clean $\mathrm{Au}(111)$ surface for coverages ranging from 0.9 to 2.9 $\mathrm{ML}$, as displayed in Figure 2. These desorption spectra

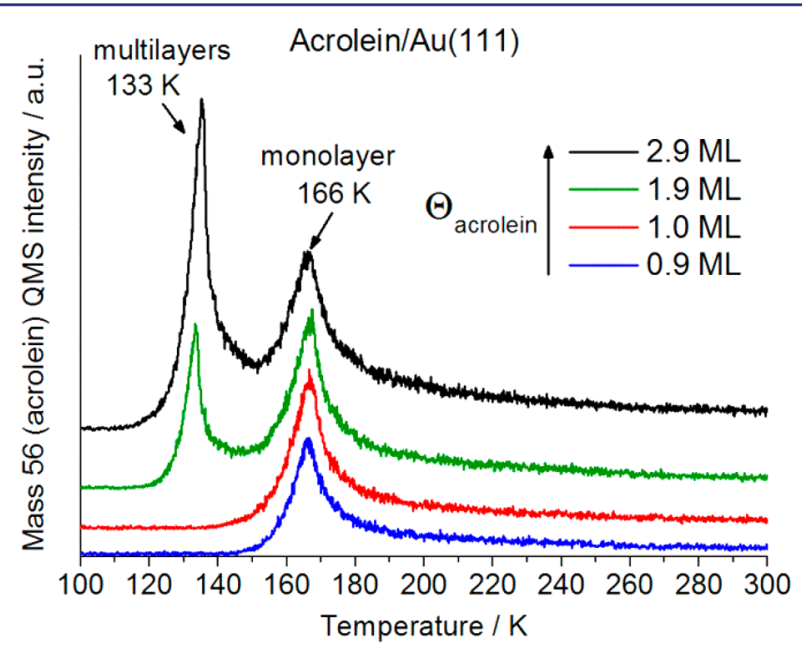

Figure 2. TPD spectra for acrolein $(m / z=56)$ desorption from $\mathrm{Au}(111)$. Acrolein was adsorbed on the $\mathrm{Au}(111)$ surface at a sample temperature of $77 \mathrm{~K}$.

exhibited two features. The high-temperature feature displayed a peak at $166 \mathrm{~K}$. This feature was populated first and saturated before the low-temperature feature began to appear, displaying first-order desorption behavior, with a desorption energy estimated to be $42.4 \mathrm{~kJ} / \mathrm{mol}$ by Redhead analysis. ${ }^{69} \mathrm{We}$ attribute this high-temperature feature to desorption of the acrolein monolayer interacting directly with the $\mathrm{Au}(111)$ surface.

The low-temperature feature displayed a peak at $\sim 133 \mathrm{~K}$. This feature appeared after the high-temperature feature had saturated and grew indefinitely as acrolein coverage was increased, displaying zero-order desorption kinetics. These characteristics are consistent with desorption of condensedphase multilayers physisorbed on top of the monolayer.

3.3. Multiple Reaction Pathways for Oxidation of Allyl Alcohol on O/Au(111). Allyl alcohol oxidation was carried out on the gold surface predosed with 0.02 and $0.15 \mathrm{ML}$ coverages of ${ }^{18} \mathrm{O}$ adatoms, as shown in Figure 3. In these experiments each specified coverage of oxygen was dosed onto the $\mathrm{Au}(111)$ surface, followed by $3.6 \mathrm{ML}$ of allyl alcohol prior to TPD. The spectra taken at each oxygen coverage displayed some similar features. Allyl alcohol multilayers desorbed at 160 $\mathrm{K}$ in the spectra for both oxygen coverages (Figure 3), displaying features characteristic of the $\alpha_{1}$ feature as observed over the clean $\mathrm{Au}(111)$ surface (Figure 1). This observation suggests that the multilayer allyl alcohol species was unaffected by the presence of oxygen adatoms on the gold surface.

Peaks characteristic of the $\alpha_{2}$ feature observed over the clean $\mathrm{Au}(111)$ surface were no longer evident in the allyl alcohol spectra in Figure 3, suggesting that the interaction resulting in this feature had been disrupted by the presence of oxygen adatoms on the gold surface at both precoverages. Attenuation of the $\alpha_{2}$ feature may result from differences in the adsorption structure of the allyl alcohol monolayer or changes to the electronic structure of surface gold atoms induced by oxygen.

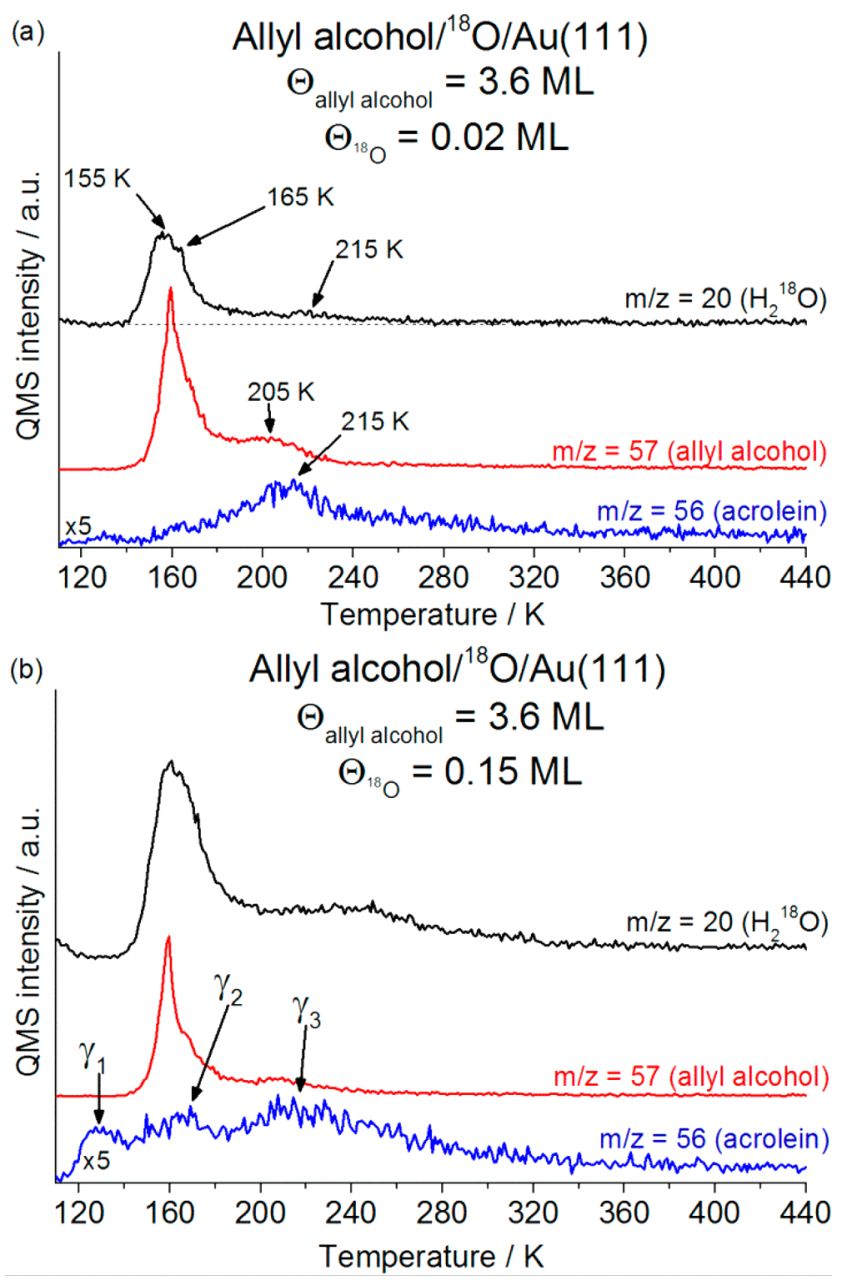

Figure 3. TPD spectra for acrolein $(m / z=56)$, allyl alcohol $(\mathrm{m} / z=$ $57)$, and $\mathrm{H}_{2}{ }^{18} \mathrm{O}(\mathrm{m} / z=20)$ following adsorption of $3.6 \mathrm{ML}$ of allyl alcohol on the $\mathrm{Au}(111)$ surface populated with (a) $0.02 \mathrm{ML}$ of ${ }^{18} \mathrm{O}$ and (b) $0.15 \mathrm{ML}$ of ${ }^{18} \mathrm{O}$. Allyl alcohol and ${ }^{18} \mathrm{O}$ were adsorbed at a sample temperature of $77 \mathrm{~K}$.

Relative to the $\beta$ feature for allyl alcohol desorption from the clean $\mathrm{Au}(111)$ surface, which displayed a peak at $195 \mathrm{~K}$, the peak of the $\beta$ feature was shifted upward in temperature to 205 and $210 \mathrm{~K}$ for the $0.02 \mathrm{ML} \mathrm{O} / \mathrm{Au}(111)$ (Figure 3a) and 0.15 $\mathrm{ML} \mathrm{O} / \mathrm{Au}(111)$ (Figure $3 \mathrm{~b}$ ) surfaces, respectively. A portion of this feature may result from desorption of unreacted allyl alcohol in the monolayer, but the shift to higher temperature suggests that some allyl alcohol associated with the monolayer interacted with the oxygen-precovered gold surface more strongly than with the clean $\mathrm{Au}(111)$ surface. The formation of an allyl alcohol-oxygen complex or a surface allyloxide species might explain this observation. Similar effects observed in the study of various alcohol species over $\mathrm{O} / \mathrm{Au}(111)$ have been suggested to result from alkoxide formation. ${ }^{22-24,70}$ Deng et al. have also suggested that the partial oxidation of allyl alcohol to acrolein proceeds through an allyloxide intermediate by analogy to experiments with isotopically labeled propene. ${ }^{29}$

We carried out DFT studies to explore the energetics associated with allyloxide formation from allyl alcohol on the oxygen-precovered $\mathrm{Au}(111)$ surface. Removal of the hydroxyl hydrogen from allyl alcohol via surface oxygen, resulting in the formation of an allyloxide and a surface hydroxyl species, as depicted in Scheme 1a, occurs with a very low activation barrier 
Scheme 1. Proposed Mechanistic Pathways for Dehydrogenation of Allyl Alcohol To Generate Allyloxide on the $\mathrm{O} / \mathrm{Au}(111)$ Surface via (a) an Oxygen Adatom and (b) a Hydroxyl Species ${ }^{a}$
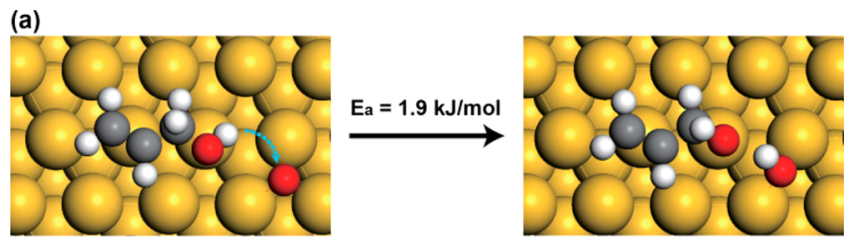

(b)

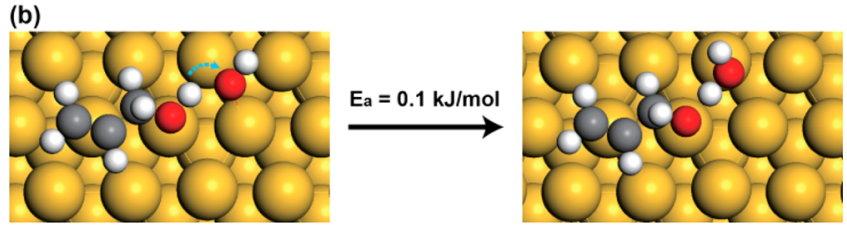

${ }^{a}$ Activation barriers $\left(E_{\mathrm{a}}\right)$ were determined via DFT calculations.

of $1.9 \mathrm{~kJ} / \mathrm{mol}$. Hydroxyl species on the $\mathrm{Au}(111)$ surface can also readily promote removal of the hydroxyl hydrogen from allyl alcohol, as depicted in Scheme 1b, via a barrier-less process $\left(E_{\mathrm{a}}=0.1 \mathrm{~kJ} / \mathrm{mol}\right)$. Reaction energy diagrams for these processes are included in Figure S1. As shown in Figure 3, the water production $\left(\mathrm{H}_{2}{ }^{18} \mathrm{O}, \mathrm{m} / z=20\right)$ spectrum for each oxygen coverage displayed a feature peaked at $155 \mathrm{~K}$, characteristic of molecular desorption of water. ${ }^{74}$ These results are also in good agreement with a DFT study in which the interactions of methanol with the $\mathrm{O} / \mathrm{Au}(111)$ and $\mathrm{OH} /$ $\mathrm{Au}(111)$ surfaces were explored. ${ }^{75}$

In addition to the molecular water desorption feature, a small shoulder at $165 \mathrm{~K}$ is also evident in each of the water production spectra in Figure 3. When oxidized over O/ $\mathrm{Au}(111)$ surfaces, simple alcohols have been shown to display water production features at $\sim 175 \mathrm{~K}$, which are characteristic of hydroxyl recombination. ${ }^{22-24}$ The shoulders observed in the spectra in Figure 3 may correlate to water produced via hydroxyl recombination on this surface. In addition to the features at 155 and $165 \mathrm{~K}$, each water production spectrum in Figure 3 displayed an additional feature at higher temperature.

For the $0.02 \mathrm{ML} \mathrm{O} / \mathrm{Au}(111)$ surface, only one acrolein feature was observed, with a peak at $215 \mathrm{~K}$, as displayed in Figure 3a. This peak shifted upward in temperature on the 0.15 ML oxygen surface to $225 \mathrm{~K}$, as observed in the feature which we have labeled $\gamma_{3}$ in Figure $3 \mathrm{~b}$ (discussion of $\gamma_{1}$ and $\gamma_{2}$ features to follow). The acrolein production feature displayed in Figure $3 a$ and the $\gamma_{3}$ feature in Figure $3 b$ coincided with the hightemperature desorption features for allyl alcohol and water. These acrolein production features appeared higher in temperature than both the multilayer (peaked at $133 \mathrm{~K}$ ) and the monolayer (peaked at $166 \mathrm{~K}$ ) features for acrolein desorption from the clean $\mathrm{Au}(111)$ surface (Figure 2). These observations indicate that acrolein production associated with the feature in Figure 3a and the $\gamma_{3}$ feature in Figure 3b occurs via a reaction-limited kinetic process on the gold surface. Similar TPD features observed in the selective oxidation of simple alcohols to aldehydes over $\mathrm{O} / \mathrm{Au}(111)$ have been attributed to the decomposition of an alkoxide intermediate. $^{22,23}$

Two additional features, which we label $\gamma_{1}$ and $\gamma_{2}$, became evident in the TPD spectrum for acrolein production when the oxygen coverage was increased from 0.02 to $0.15 \mathrm{ML}$ (Figure 3b). The lowest-temperature feature $\left(\gamma_{1}\right)$ displayed a peak at $125 \mathrm{~K}$. To probe the process responsible for generating this feature, we carried out the RMBS experiment depicted in Figure 4, in which acrolein production was monitored while

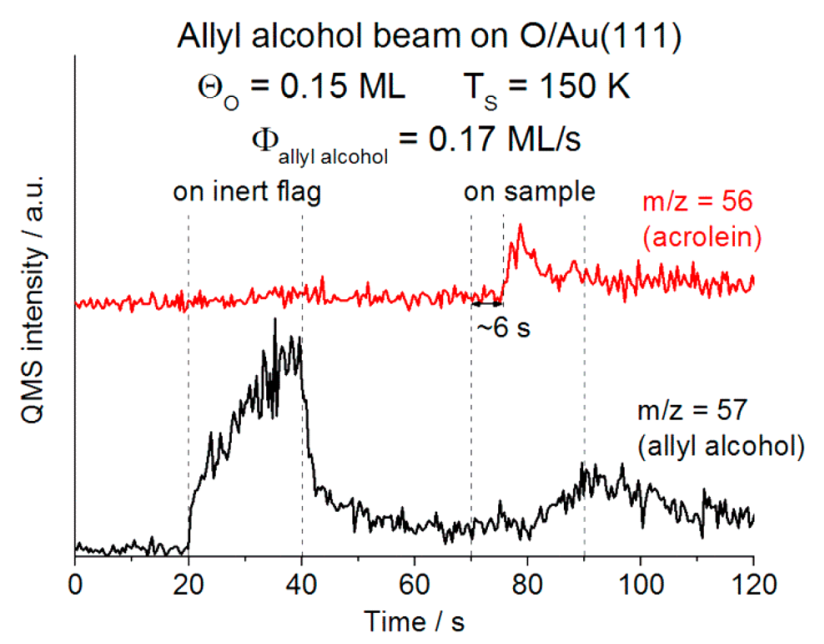

Figure 4. RMBS of allyl alcohol on $0.15 \mathrm{ML}$ of $\mathrm{O} / \mathrm{Au}(111)$. Allyl alcohol was dosed onto the sample at a surface temperature of $150 \mathrm{~K}$ while monitoring acrolein $(m / z=56)$ production and allyl alcohol $(m / z=57)$ desorption via QMS. Atomic oxygen was adsorbed at a sample temperature of $77 \mathrm{~K}$. The flux of allyl alcohol on the surface was $0.17 \mathrm{ML} / \mathrm{s}$.

allyl alcohol was dosed onto the $0.15 \mathrm{ML} \mathrm{O} / \mathrm{Au}(111)$ surface held at $150 \mathrm{~K}$ (above the temperature at which the $\gamma_{1}$ feature appeared, but below the temperature at which the $\gamma_{2}$ feature appeared). In this experiment, a molecular beam of allyl alcohol was impinged onto an inert flag held in front of the $\mathrm{O} / \mathrm{Au}(111)$ sample for $20 \mathrm{~s}$ (time $=20-40 \mathrm{~s}$ ) to establish baseline signals for acrolein and allyl alcohol and then onto the $\mathrm{O} / \mathrm{Au}(111)$ sample for $20 \mathrm{~s}$ (time $=70-90 \mathrm{~s}$ ) to observe acrolein production dynamics. An induction period of $\sim 6 \mathrm{~s}$ was observed, as shown in Figure 4, prior to acrolein production. At the given allyl alcohol flux rate of $0.17 \mathrm{ML} / \mathrm{s}$, this exposure roughly corresponds to the dosing equivalent required to saturate the $\beta$ feature (monolayer) of allyl alcohol on the clean $\mathrm{Au}(111)$ surface (Figure 1). This observation may suggest that acrolein produced on the $\mathrm{O} / \mathrm{Au}(111)$ surface during the experiment diffused away from the monolayer and desorbed from a multilayer-like state once a sufficient coverage of allyl alcohol had been dosed. Furthermore, the temperature at which the $\gamma_{1}$ feature appeared in Figure $3 \mathrm{~b}$ coincides with the desorption feature of acrolein multilayers on the clean $\mathrm{Au}(111)$ surface (Figure 2). These observations suggest that the $\gamma_{1}$ acrolein production feature in Figure $3 b$ was the result of acrolein desorption from a multilayer-like state, and the process responsible for its production was desorption-limited.

We suggest that, for multilayer coverages of allyl alcohol on the $0.15 \mathrm{ML} \mathrm{O} / \mathrm{Au}(111)$ surface, acrolein was produced at or below the temperature region associated with the $\gamma_{1}$ feature, and diffused into the overlying multilayers of allyl alcohol, desorbing from a multilayer-like state. To test this mechanism further, we carried out an experiment in which 0.6 ML of acrolein was dosed on the clean $\mathrm{Au}(111)$ surface, followed by 3.6 ML of allyl alcohol before carrying out TPD (Figure S2). Despite having been dosed directly onto the gold surface, acrolein desorbed at a lower temperature than allyl alcohol in a 
single feature characteristic of multilayer desorption. Monolayer acrolein desorption was not observed during this TPD experiment, supporting our assertion that acrolein associated with the $\gamma_{1}$ production feature diffused into the allyl alcohol multilayers prior to desorption.

The intermediate-temperature acrolein production feature, denoted $\gamma_{2}$, displayed a peak at $163 \mathrm{~K}$ as shown in Figure $3 \mathrm{~b}$. This peak temperature roughly coincided with the desorption peak of the acrolein monolayer on the clean $\mathrm{Au}(111)$ surface (Figure 2). The $\gamma_{2}$ feature may result from acrolein produced at lower temperature desorbing from a monolayer-like state or from acrolein production due to the decomposition of reactive intermediates on the surface. The results displayed in Figure S2 would seem to suggest the latter because the clean $\mathrm{Au}(111)$ surface populated with acrolein and allyl alcohol did not display the monolayer feature in the acrolein desorption spectrum. Therefore, we would expect acrolein produced at low temperature to desorb from a multilayer-like state, as suggested for the $\gamma_{1}$ feature.

The observation of both reaction-limited and desorptionlimited kinetic processes indicates that the partial oxidation of allyl alcohol to acrolein proceeds via multiple reaction pathways over the $\mathrm{O} / \mathrm{Au}(111)$ surface. Propagation of low-temperature features $\left(\gamma_{1}\right.$ and $\left.\gamma_{2}\right)$ occurred as the oxygen coverage was increased from 0.02 to $0.15 \mathrm{ML}$, as displayed in Figure 3. Only the $\gamma_{3}$ acrolein production feature was observed at the oxygen adatom coverage of $0.02 \mathrm{ML}$ (Figure 3a). The $\gamma_{1}$ and $\gamma_{2}$ features grew as oxygen coverage was increased, while the size of the $\gamma_{3}$ feature did not significantly change (Figure 3b). These observations suggest that the surface arrangement of oxygen adatoms is instrumental in dictating the oxidation kinetics of allyl alcohol on $\mathrm{O} / \mathrm{Au}(111)$.

DFT and UHV studies have shown that oxygen adatoms on the $\mathrm{Au}(111)$ surface can induce significant changes to the gold surface morphology. ${ }^{76,77}$ Several types of oxygen-gold interactions are known to occur on this surface, resulting in variations in the reactivity of the oxygen. The most reactive form of oxygen on the $\mathrm{Au}(111)$ surface, chemisorbed oxygen, binds in the 3 -fold coordination sites. ${ }^{78}$ Chemisorbed oxygen dominates for exposures at low coverages and low surface temperatures. ${ }^{78}$ The other forms of oxygen on gold, surface oxide and bulk oxide, are less reactive and result from stronger interactions between gold and oxygen atoms. Generation of gold oxide causes significant restructuring of the (111) surface, resulting in the release of gold atoms into nanostructures that assemble on the surface. ${ }^{79}$ High oxygen coverages and high surface temperatures have been shown to favor the formation of gold oxides. ${ }^{78}$ The allyl alcohol oxidation experiments carried out in this study all utilized relatively low oxygen coverages dosed at low surface temperature. It is unlikely that significant amounts of gold oxide were generated on the surface in our experiments. A study from Baker et al. showed that, even with dosing at $200 \mathrm{~K}$, only chemisorbed oxygen was detected on the $\mathrm{Au}(111)$ surface until the oxygen coverage was increased beyond $0.5 \mathrm{ML}^{77} \mathrm{We}$ suggest that under the conditions employed in our study, only chemisorbed oxygen adatoms were present on all of the oxygen-precovered $\mathrm{Au}(111)$ surfaces.

Initial oxygen coverages may prove to direct relative populations of reactive intermediates on the $\mathrm{Au}(111)$ surface, and adsorbed allyloxide species may react differently with atomic oxygen adatoms and hydroxyl species on the $\mathrm{Au}(111)$ surface, causing changes to the patterns of reactivity as surface oxygen coverage is increased. It should be noted that the presence of water and hydroxyl species has been shown to significantly affect catalytic processes over gold surfaces. ${ }^{34,35}$ We performed DFT calculations to further investigate the influence of oxygen and various intermediates on acrolein production over the $\mathrm{Au}(111)$ surface. As mentioned previously, allyl alcohol is readily dehydrogenated to yield allyloxide via removal of its hydroxyl hydrogen by either atomic oxygen or hydroxyl species on the gold surface. The second dehydrogenation step (removal of an $\alpha$-hydrogen from the allyloxide) is facile if atomic oxygen is present on the surface, occurring with an activation energy of $10.6 \mathrm{~kJ} / \mathrm{mol}$, whereas the process is less facile if a surface hydroxyl species is the oxidizing agent $\left(E_{\mathrm{a}}=\right.$ $36.5 \mathrm{~kJ} / \mathrm{mol}$ ). The reaction energy diagrams for these processes are depicted in Figure S1. We expect that dehydrogenation of allyloxide to generate acrolein and surface hydrogen would be a highly unfavorable process, as the instability of the goldhydride has been well documented. ${ }^{80,81}$ Furthermore, this dehydrogenation process was shown to be unfavorable for methoxide on the $\mathrm{Au}(111)$ surface. $^{75}$ Therefore, we suggest that the $\gamma_{1}$ acrolein production feature is the result of $\alpha$ hydrogen removal from allyloxide via surface oxygen adatoms, as shown in Scheme 2a. The low activation barrier of only 10.6

\section{Scheme 2. Proposed Mechanistic Pathways for $\alpha$ - Dehydrogenation of Allyloxide To Generate Acrolein on the O/Au(111) Surface ${ }^{a}$}
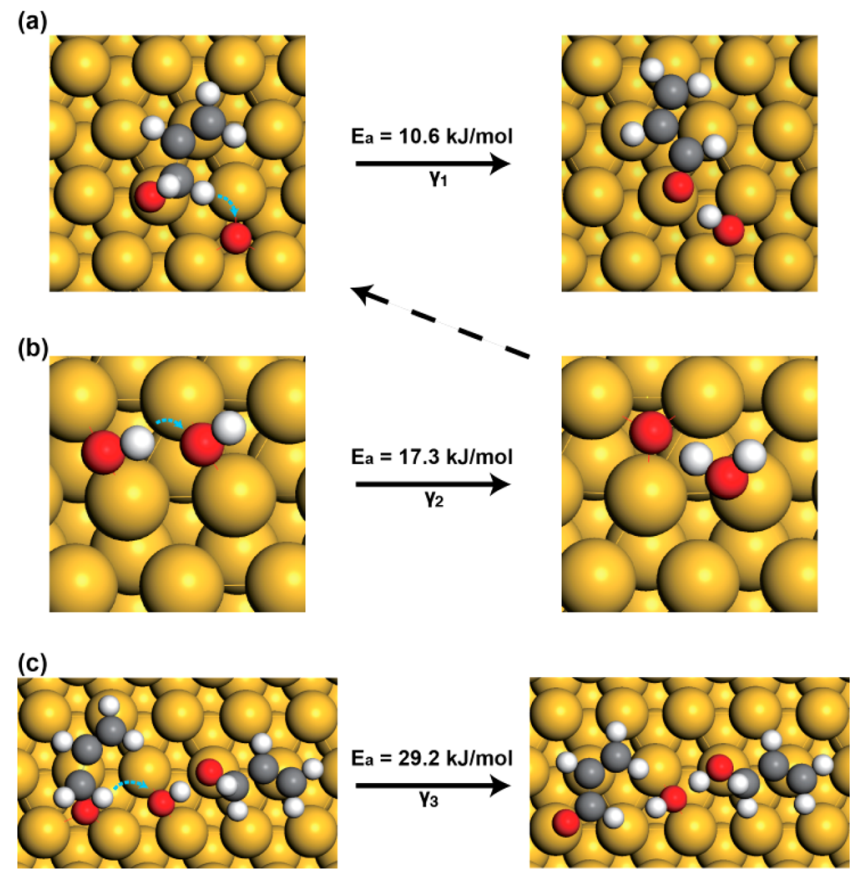

${ }^{a}$ Activation barriers $\left(E_{\mathrm{a}}\right)$ were determined via DFT calculations.

$\mathrm{kJ} / \mathrm{mol}$ for this process would allow it to occur at temperatures consistent with desorption-limited acrolein production. Also, this process would not be expected to occur at very low oxygen coverages, as observed in Figure 3a. At low oxygen coverages, a single allyl alcohol species would be unlikely to encounter a cluster of oxygen adatoms on the surface. Each oxygen would be converted to a hydroxyl species via removal of a hydroxyl hydrogen from allyl alcohol in the allyloxide formation process prior to interaction with allyloxide on the surface.

We suggest that the $\gamma_{2}$ acrolein production feature is also due to allyloxide dehydrogenation via surface oxygen; however, in 
this case the surface oxygen is generated by the recombination of two hydroxyl species, producing $\mathrm{H}_{2} \mathrm{O}$ and an oxygen adatom, as depicted in Scheme $2 \mathrm{~b}$. We calculated the activation barrier for this process to be $17.3 \mathrm{~kJ} / \mathrm{mol}$ (reaction energy diagram in Figure S1). After hydroxyl recombination, the resulting oxygen adatom would be free to induce $\alpha$-hydrogen removal via the mechanism suggested in Scheme 2a. In this sense, the hydroxyl species acts to poison the surface toward the low-temperature oxidation pathway, inhibiting this process until sufficient energy has been provided to cause hydroxyl recombination and regenerate oxygen adatoms. The temperature at which the $\gamma_{2}$ feature appeared in Figure $3 \mathrm{~b}$ is the approximate onset temperature for hydroxyl recombination on the $\mathrm{Au}(111)$ surface. $^{38}$

Occurrence of the hydroxyl recombination pathway is further substantiated by TPD of allyl alcohol carried out on $\mathrm{H}_{2} \mathrm{O} / \mathrm{O}$ / $\mathrm{Au}(111)$, displayed in Figure 5. Several studies have suggested

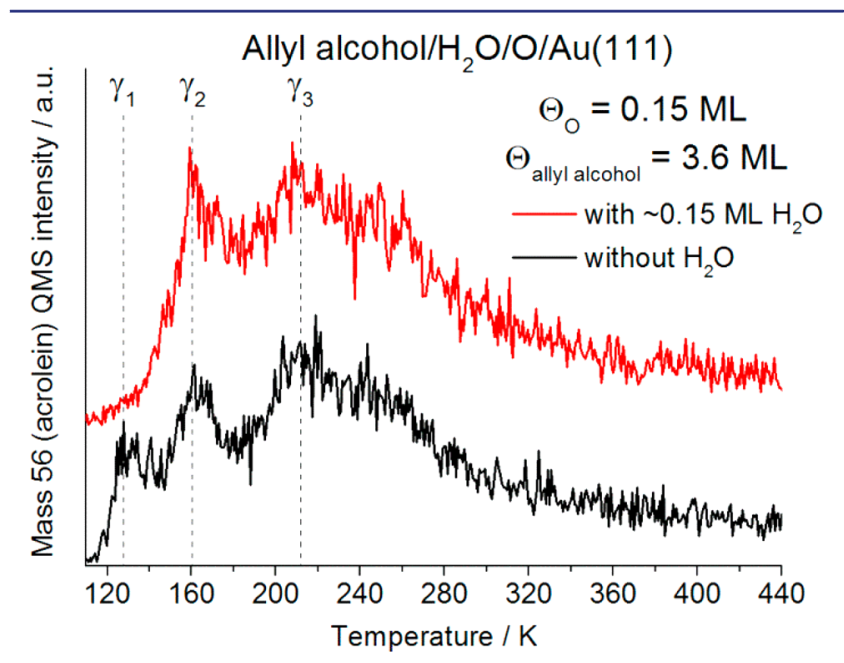

Figure 5. TPD spectra for acrolein $(m / z=56)$ following adsorption of 3.6 ML of allyl alcohol on the $\mathrm{Au}(111)$ surface populated with 0.15 $\mathrm{ML}$ of atomic oxygen and $0.15 \mathrm{ML}$ of atomic oxygen followed by $\sim 0.15 \mathrm{ML}$ of $\mathrm{H}_{2} \mathrm{O}$. All species were adsorbed at a sample temperature of $77 \mathrm{~K}$.

that hydroxyl formation from water and oxygen atoms on the $\mathrm{Au}(111)$ surface is a facile process that occurs at temperatures as low as $77 \mathrm{~K}^{38,82}$ therefore, we would expect the $\mathrm{H}_{2} \mathrm{O} / \mathrm{O}$ / $\mathrm{Au}(111)$ surface to be populated with hydroxyl species rather than oxygen adatoms at the time of allyl alcohol dosing. When allyl alcohol oxidation was carried out over this surface, the $\gamma_{1}$ acrolein production feature was inhibited and the $\gamma_{2}$ feature was enhanced. These observations suggest that atomic oxygen is required for the low-temperature $\left(\gamma_{1}\right)$ pathway and that hydroxyl species are associated with the intermediate-temperature $\left(\gamma_{2}\right)$ pathway, in support of our proposed mechanism.

The $\gamma_{3}$ feature is suggested to result from removal of an $\alpha$ hydrogen from allyloxide via a hydroxyl species in a process mediated by a second allyloxide, as shown in Scheme $2 \mathrm{c}$. As mentioned previously, the DFT-derived activation barrier for removal of an $\alpha$-hydrogen from allyloxide via a single hydroxyl species is relatively high $(36.5 \mathrm{~kJ} / \mathrm{mol})$; however, if this process is mediated by the interaction of a second allyloxide, the activation barrier is decreased to $29.2 \mathrm{~kJ} / \mathrm{mol}$. Reaction energy diagrams for these processes are displayed in Figure S1. The allyloxide mediator species partially abstracts hydrogen away from the surface hydroxyl species, as suggested by elongation of the surface hydroxyl $\mathrm{O}-\mathrm{H}$ bond from $1.00 \AA$ on the clean $\mathrm{Au}(111)$ surface to $1.05 \AA$ in the transition state for this dehydrogenation process. This elongation increases the oxidizing potential of the hydroxyl species and allows abstraction the $\alpha$-hydrogen from the reactant allyloxide to occur more readily. For this process, we would expect production of both water and allyl alcohol to be observed in addition to acrolein since hydrogen transfer between the resulting surface species would be facile. Processes resulting in the generation of water and allyloxide $\left(E_{\mathrm{a}}=0.1 \mathrm{~kJ} / \mathrm{mol}\right)$ or allyl alcohol and a hydroxyl species $\left(E_{\mathrm{a}}=1.5 \mathrm{~kJ} / \mathrm{mol}\right)$ both occur readily. Reaction energy diagrams for this process are displayed in Figure S1.

To probe the $\gamma_{3}$ acrolein production process in our UHV system, we carried out allyl alcohol oxidation on the $\mathrm{Au}(111)$ surface populated with deuterated hydroxyl (d-hydroxyl) species. Ojifinni et al. showed that $\mathrm{D}_{2} \mathrm{O}$ readily forms dhydroxyl species upon interaction with oxygen adatoms on the $\mathrm{Au}(111)$ surface. ${ }^{38}$ The authors of that study showed that, upon heating the $\mathrm{Au}(111)$ surface populated with $0.08 \mathrm{ML}$ of $\mathrm{D}_{2}{ }^{16} \mathrm{O}$ and $0.18 \mathrm{ML}$ of ${ }^{18} \mathrm{O}$, a signal for $m / z=22\left(\mathrm{D}_{2}{ }^{18} \mathrm{O}\right)$ was observed in the corresponding TPD spectrum, indicating that deuterium had transferred from the water that was impinged on the surface to the surface oxygen adatoms. ${ }^{38}$ Furthermore, significant swapping of surface oxygen atoms with oxygen from the water was demonstrated by monitoring the TPD signals for $m / z=32\left({ }^{16} \mathrm{O}_{2}\right), m / z=34\left({ }^{16} \mathrm{O}^{18} \mathrm{O}\right)$, and $m / z=36\left({ }^{18} \mathrm{O}_{2}\right)$. We dosed $0.15 \mathrm{ML}$ of $\mathrm{D}_{2}{ }^{16} \mathrm{O}$ on the $\mathrm{Au}(111)$ surface precovered with $0.15 \mathrm{ML}$ of ${ }^{18} \mathrm{O}$ to generate a surface populated with $\mathrm{d}$ hydroxyl species. Upon this surface, we dosed 3.6 ML of allyl alcohol, and then we carried out TPD while monitoring the production of acrolein, $\mathrm{D}_{2}{ }^{18} \mathrm{O}$, and $\mathrm{HD}^{18} \mathrm{O}$ (Figure 6). In the

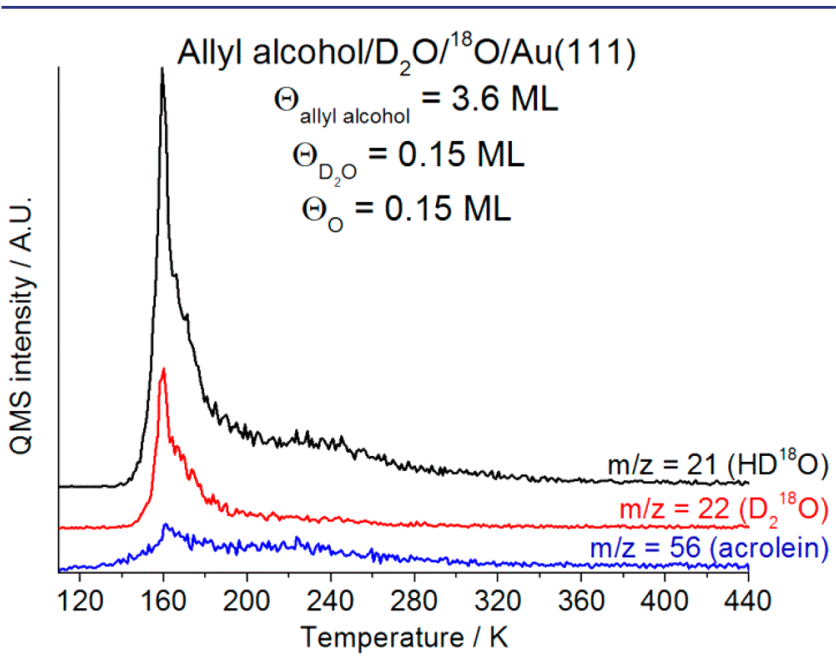

Figure 6. TPD spectra for acrolein $(m / z=56), \mathrm{HD}^{18} \mathrm{O}(m / z=21)$, and $\mathrm{D}_{2}{ }^{18} \mathrm{O}(\mathrm{m} / z=22)$ following adsorption of $3.6 \mathrm{ML}$ of allyl alcohol on the $\mathrm{Au}(111)$ surface populated with $0.15 \mathrm{ML}$ of ${ }^{18} \mathrm{O}$ and $0.15 \mathrm{ML}$ of $\mathrm{D}_{2}{ }^{16} \mathrm{O}$. All species were adsorbed at a sample temperature of $77 \mathrm{~K}$.

temperature region correlating to $\gamma_{3}$ acrolein production, generation of $\mathrm{HD}^{18} \mathrm{O}(\mathrm{m} / z=21)$ was observed, while $\mathrm{D}_{2}{ }^{18} \mathrm{O}$ $(m / z=22)$ was not. These observations are consistent with the mechanism depicted in Scheme 2c. Because the allyl alcohol dosed onto the surface was not deuterated, we would expect $\mathrm{HD}^{18} \mathrm{O}$ to be produced via $\alpha$-hydrogen abstraction from the resulting allyloxide, while $\mathrm{D}_{2}{ }^{18} \mathrm{O}$ would not be generated since the allyloxide was not deuterated. Furthermore, acrolein 
production associated with the $\gamma_{3}$ feature was less pronounced for the $\mathrm{D}_{2} \mathrm{O} / \mathrm{O} / \mathrm{Au}\left(111\right.$ ) surface (Figure 6) than for the $\mathrm{H}_{2} \mathrm{O}$ / $\mathrm{O} / \mathrm{Au}(111)$ surface (Figure 5), suggesting a kinetic isotope effect (KIE) had occurred when d-hydroxyl species were populated on the gold surface. The observation of a KIE would be expected since abstraction of the $\mathrm{O}-\mathrm{H} / \mathrm{D}$ bond is associated with the rate-limiting step of our proposed mechanism for the $\gamma_{3}$ acrolein production pathway.

Oxygen swapping from surface adatoms into the acrolein product or the unreacted allyl alcohol was not observed in any of the spectra taken in this study (data not shown), suggesting that the $\mathrm{C}-\mathrm{O}$ bond was not broken in the oxidation of allyl alcohol on $\mathrm{O} / \mathrm{Au}(111)$. It has been suggested that the presence of an intact $\mathrm{C}-\mathrm{O}$ bond facilitates $\alpha$-hydrogen cleavage of alkoxide species over various surfaces, ${ }^{83,84}$ further supporting our proposed mechanisms.

Allyl alcohol and 1-propanol have similar structures but display different TPD features upon oxidation on the $\mathrm{O} /$ $\mathrm{Au}(111)$ surface. Although the mechanism of partial oxidation which we have determined for allyl alcohol is similar to that suggested for 1-propanol on the $\mathrm{O} / \mathrm{Au}(111)$ surface (hydroxyl hydrogen removal to generate a surface alkoxide followed by $\alpha$ hydrogen removal from the alkoxide), ${ }^{23}$ allyl alcohol displayed three aldehyde production features $\left(\gamma_{1}, \gamma_{2}\right.$, and $\left.\gamma_{3}\right)$ when oxidized on the $\mathrm{O} / \mathrm{Au}(111)$ surface, whereas 1-propanol displayed only one feature. ${ }^{23}$ The temperature at which the peak for propanal, the aldehyde product of 1-propanol oxidation, occurred was $\sim 200 \mathrm{~K},{ }^{23}$ which is analogous to the $\gamma_{3}$ feature we observed in Figure 3 for acrolein production. This observation may suggest that 1-propanol and other simple alcohols that display similar TPD features for oxidation on the $\mathrm{O} / \mathrm{Au}(111)$ surface $^{22,23}$ do not observe the same set of reaction pathways as allylic alcohols with respect to surface oxygen adatoms and hydroxyl species on the $\mathrm{Au}(111)$ surface. These differences may begin with alkoxide formation. The observation of predominantly molecular $\mathrm{H}_{2} \mathrm{O}$ desorption for allyl alcohol $\mathrm{TPD}$ on $\mathrm{O} / \mathrm{Au}(111)$ rather than hydroxyl recombination as observed for TPD of simple alcohols on $\mathrm{O} / \mathrm{Au}(111)^{22-24}$ suggests that the allyloxide species can be formed via hydroxyl hydrogen abstraction via either oxygen adatoms or surface hydroxyl species. Our DFT results support this conclusion. Simple alcohols may only generate alkoxides via hydrogen abstraction by oxygen adatoms on the surface and not by hydroxyl species, and the resulting differences in surface intermediate populations may drive reaction kinetics toward different pathways. However, this prospect is not supported in the DFT study carried out by Chang et al. for methanol interaction with $\mathrm{O} / \mathrm{Au}(111)$, which suggested that methoxide can be readily formed via hydroxyl hydrogen removal from methanol by either oxygen adatoms or hydroxyl species on the gold surface. $^{75}$

The alkoxide intermediate present on the gold surface during oxidation of 1-propanol may interact strongly with hydroxyl species in a surface complex, hindering recombination and inhibiting a potential $\gamma_{2}$ production pathway. Alternatively, differences in the reactivity of the $\alpha$-hydrogen due to the lack of allylic nature may inhibit the activity of the 1-propyl alkoxide toward the $\gamma_{1}$ production pathway. It is possible that 1-propanol (and other simple alcohols) can undergo multiple reaction pathways on the $\mathrm{Au}(111)$ surface due to the relative populations of surface intermediates, but these pathways simply cannot be observed in TPD spectra because the required surface ensembles are not sampled.
The oxidation of 2-propanol to acetone on $\mathrm{O} / \mathrm{Au}(111)$ was demonstrated by Gong et al. to display features with peaks at $\sim 180$ and $210 \mathrm{~K}^{23}$ Elaboration as to the reason for the observation of multiple features was not provided in this work. It is possible that these features resulted from the oxidation of the 2-propyl alkoxide via different surface species on the gold surface. Unless hindered from desorption by interaction in a surface complex, it seems unlikely that a reaction process analogous to the $\gamma_{1}$ pathway observed for allyl alcohol oxidation occurred for 2-propanol oxidation. Multilayer desorption of acetone on the clean $\mathrm{Au}(111)$ surface has been shown to occur at $132 \mathrm{~K},{ }^{85}$ well below the onset of the acetone production feature in the study by Gong et al. ${ }^{23}$ The observation of multiple production features for 2-propanol oxidation may suggest that multiple reaction pathways occurred; however, potential differences in reaction pathway brought on by the presence of the carbon-carbon double bond cannot be ruled out, and the observation of multiple reaction pathways may be unique to allylic alcohols.

The differences we observed in the reactivity of hydroxyl species and oxygen adatoms on the $\mathrm{Au}(111)$ surface are of particular interest. Zope et al. showed that hydroxyl species are directly involved in the partial oxidation of ethanol and glycerol to their corresponding carboxylic acids over gold catalysts in basic aqueous media. ${ }^{47}$ These processes were suggested to proceed first through gold-catalyzed partial oxidation to generate the corresponding aldehydes. ${ }^{47}$ Via a combination of DFT studies and experiments with isotopically labeled water $\left(\mathrm{H}_{2}{ }^{18} \mathrm{O}\right)$ and molecular oxygen $\left({ }^{18} \mathrm{O}_{2}\right)$, the authors showed that oxygen from the water rather than from $\mathrm{O}_{2}$ was incorporated into the resulting product species and suggested that $\mathrm{O}_{2}$ acted, instead, to scavenge electrons from the gold particles after oxidation of alcohol had occurred via a hydroxyl species, regenerating the hydroxyl and closing the catalytic cycle. ${ }^{47}$

Our results show that oxidation of allyl alcohol via hydroxyl species is possible but occurs with a higher activation barrier than hydroxyl recombination on the gold surface followed by oxidation of allyloxide via a surface oxygen adatom. The activation barrier for oxidation of allyloxide via a hydroxyl species is lowered by mediation from a second surface allyloxide; therefore, we suggest that the relative proportions of reactive intermediates on the gold surface dictate the mechanism for allyl alcohol oxidation. For conditions under which large concentrations of hydroxyl species are expected to reside on the gold surface, hydroxyl recombination followed by oxidation of allyloxide via surface oxygen would be the most likely pathway. For conditions with low surface hydroxyl concentrations, dehydrogenation of allyloxide via a surface complex consisting of a hydroxyl species interacting with a second allyloxide would be expected to dominate. Such pathways may be broadly applicable to other alcohol species as well.

\section{CONCLUSIONS}

Allyl alcohol adsorbs and desorbs molecularly from the clean $\mathrm{Au}(111)$ surface without undergoing any chemical transformations. Oxidation of allyl alcohol to acrolein occurs over oxygen-precovered $\mathrm{Au}(111)$ surfaces and proceeds via a mechanism similar to those suggested for other alcohol species over gold catalysts: dehydrogenation of the hydroxyl hydrogen to form a surface alkoxide followed by $\alpha$-dehydrogenation of the alkoxide to selectively generate the aldehyde product. 
Oxidation of allyl alcohol to acrolein occurs via three different reaction pathways over the $\mathrm{Au}(111)$ surface, dictated by the relative populations of atomic oxygen and hydroxyl species on the surface. Similar results have not been observed in the TPD spectra for oxidation of simple alcohols on the $\mathrm{Au}(111)$ surface, which may suggest that allylic alcohols and simple alcohols react differently in the presence of various surface intermediates or that aldehydes produced on the surface during oxidation of simple alcohols by an analogous mechanism are retained on the surface in structures that desorb at higher temperatures.

Our observations may provide insight into the pathways for oxidation of alcohols over gold surfaces, in both vapor- and liquid-phase systems. Our results suggest that allyl alcohol is most readily oxidized to acrolein via oxygen adatoms on the $\mathrm{Au}(111)$ surface. If a single allyl alcohol molecule encounters multiple surface oxygen adatoms, then this process can occur at very low temperatures. A hydroxyl species can also oxidize the reactive intermediate, allyloxide, but does so via a process with a higher activation barrier. Yet another oxidative pathway involves the generation of surface oxygen by hydroxyl recombination, followed by oxidation via the low-temperature pathway. This process may dominate in the high-pH conditions under which alcohol oxidation has been shown to occur readily over gold catalysts.

Our work may also aid in the general understanding of the reactivity of oxygen and hydroxyl species on gold surfaces. Such reactions are of great interest, considering the enhancement effect many gold catalysts display upon interaction with water. Water is present to some extent in most catalytic systems, whether as an impurity, reactant, product, or solvent. Accordingly, water may have unknown/unexplored effects on a host of catalytic reactions. Therefore, thorough consideration of the effects of water is necessary when assessing a catalytic system, particularly when oxidation reactions are involved.

\section{ASSOCIATED CONTENT}

\section{S Supporting Information}

Displacement of $\mathrm{H}_{2}{ }^{16} \mathrm{O}$ from walls of UHV chamber by allyl alcohol, acrolein and allyl alcohol desorption from the clean $\mathrm{Au}(111)$ surface, and DFT-calculated reaction energy diagrams for acrolein production on the $\mathrm{Au}(111)$ surface. This material is available free of charge via the Internet at http://pubs.acs.org.

\section{AUTHOR INFORMATION}

\section{Corresponding Author}

mullins@che.utexas.edu

\section{Notes}

The authors declare no competing financial interest.

\section{ACKNOWLEDGMENTS}

We are thankful for the generous support of the Department of Energy (DE-FG02-04ER15587 [C.B.M.] and DE-FG0213ER16428 [G.H.]) and the Welch Foundation (Grants F1436 [C.B.M.] and F-1841 [G.H.]). G.M.M. acknowledges the National Science Foundation for a Graduate Research Fellowship. Cara R. Touretzky and Richard C. Pattison are gratefully acknowledged for aid with instrument optimization.

\section{REFERENCES}

(1) Bond, G. C.; Sermon, P. A.; Webb, G.; Buchanan, D. A.; Wells, B. J. Chem. Soc., Chem. Commun. 1973, 5.
(2) Haruta, M.; Kobayashi, T.; Sano, H.; Yamada, N. Chem. Lett. 1987, 405.

(3) Hutchings, G. J. J. Catal. 1985, 96, 292.

(4) Hashmi, A. S. K.; Hutchings, G. J. Angew. Chem., Int. Ed. 2006, 45, 7896.

(5) Bond, G. C.; Thompson, D. T. Catal. Rev.-Sci. Eng. 1999, 41, 319

(6) Haruta, M.; Daté, M. Appl. Catal. A Gen. 2001, 222, 427.

(7) Haruta, M. Chem. Rec. 2003, 3, 75.

(8) Gong, J. Chem. Rev. 2012, 112, 2987.

(9) Gong, J.; Mullins, C. B. Acc. Chem. Res. 2009, 42, 1063.

(10) Pan, M.; Brush, A. J.; Pozun, Z. D.; Ham, H. C.; Yu, W.-Y.; Henkelman, G.; Hwang, G. S.; Mullins, C. B. Chem. Soc. Rev. 2013, 42, 5002.

(11) Pan, M.; Gong, J.; Dong, G.; Mullins, C. B. Acc. Chem. Res. 2014, 47,750 .

(12) Madix, R. J.; Friend, C. M.; Liu, X. J. Catal. 2008, 258, 410.

(13) Min, B. K.; Friend, C. M. Chem. Rev. 2007, 107, 2709.

(14) Rodriguez, J. A.; Senanayake, S. D.; Stacchiola, D.; Liu, P.; Hrbek, J. Acc. Chem. Res. 2014, 47, 773.

(15) Rodriguez, J. A. Catal. Today 2011, 160, 3.

(16) Prati, L.; Rossi, M. J. Catal. 1998, 176, 552.

(17) Davis, S. E.; Ide, M. S.; Davis, R. J. Green Chem. 2013, 15, 17.

(18) Abad, A.; Concepción, P.; Corma, A.; García, H. Angew. Chem., Int. Ed. 2005, 44, 4066.

(19) Biella, S.; Rossi, M. Chem. Commun. 2003, 378.

(20) Mori, K.; Hara, T.; Mizugaki, T.; Ebitani, K.; Kaneda, K. J. Am. Chem. Soc. 2004, 126, 10657.

(21) Enache, D. I.; Edwards, J. K.; Landon, P.; Solsona-Espriu, B.; Carley, A. F.; Herzing, A. A.; Watanabe, M.; Kiely, C. J.; Knight, D. W.; Hutchings, G. J. Science 2006, 311, 362.

(22) Gong, J.; Mullins, C. B. J. Am. Chem. Soc. 2008, 130, 16458.

(23) Gong, J.; Flaherty, D. W.; Yan, T.; Mullins, C. B. ChemPhysChem 2008, 9, 2461.

(24) Yan, T.; Gong, J.; Mullins, C. B. J. Am. Chem. Soc. 2009, 131, 16189.

(25) Liu, X.; Friend, C. M. Langmuir 2010, 26, 16552.

(26) Liu, X.; Xu, B.; Haubrich, J.; Madix, R. J.; Friend, C. M. J. Am. Chem. Soc. 2009, 131, 5757.

(27) Xu, B.; Madix, R. J.; Friend, C. M. J. Am. Chem. Soc. 2010, 132, 16571.

(28) Xu, B.; Liu, X.; Haubrich, J.; Friend, C. M. Nat. Chem. 2010, 2, 61.

(29) Deng, X.; Min, B. K.; Liu, X.; Friend, C. M. J. Phys. Chem. B 2006, 110, 15982.

(30) Abad, A.; Almela, C.; Corma, A.; García, H. Chem. Commun. 2006, 3178.

(31) Davis, J. L.; Barteau, M. A. J. Mol. Catal. 1992, 77, 109.

(32) Shekhar, R.; Barteau, M. A. Surf. Sci. 1994, 319, 298.

(33) Abad, A.; Corma, A.; García, H. Pure Appl. Chem. 2007, 79, 1847.

(34) Mullen, G. M.; Gong, J.; Yan, T.; Pan, M.; Mullins, C. B. Top. Catal. 2013, 56, 1499.

(35) Ide, M. S.; Davis, R. J. Acc. Chem. Res. 2014, 47, 825.

(36) Daté, M.; Okumura, M.; Tsubota, S.; Haruta, M. Angew. Chem., Int. Ed. 2004, 43, 2129.

(37) Ojeda, M.; Zhan, B.-Z.; Iglesia, E. J. Catal. 2012, 285, 92.

(38) Ojifinni, R. A.; Froemming, N. S.; Gong, J.; Pan, M.; Kim, T. S.; White, J. M.; Henkelman, G.; Mullins, C. B. J. Am. Chem. Soc. 2008, 130,6801

(39) Kim, T. S.; Gong, J.; Ojifinni, R. A.; White, J. M.; Mullins, C. B. J. Am. Chem. Soc. 2006, 128, 6282.

(40) Gao, F.; Wood, T. E.; Goodman, D. W. Catal. Lett. 2009, 134, 9.

(41) Bond, G. C.; Thompson, D. T. Gold Bull. 2000, 33, 41.

(42) Schubert, M. M.; Venugopal, A.; Kahlich, M. J.; Plzak, V.; Behm, R. J. J. Catal. 2004, 222, 32.

(43) Huang, J.; Akita, T.; Faye, J.; Fujitani, T.; Takei, T.; Haruta, M. Angew. Chem., Int. Ed. 2009, 48, 7862. 
(44) Lee, S.; Molina, L. M.; López, M. J.; Alonso, J. A.; Hammer, B.; Lee, B.; Seifert, S.; Winans, R. E.; Elam, J. W.; Pellin, M. J.; Vajda, S. Angew. Chem., Int. Ed. 2009, 48, 1467.

(45) Ojeda, M.; Iglesia, E. Chem. Commun. 2009, 352.

(46) Ueda, A.; Oshima, T.; Haruta, M. Appl. Catal. B Environ. 1997, $12,81$.

(47) Zope, B. N.; Hibbitts, D. D.; Neurock, M.; Davis, R. J. Science 2010, 330, 74.

(48) Carrettin, S.; McMorn, P.; Johnston, P.; Griffin, K.; Hutchings, G. J. Chem. Commun. 2002, 696.

(49) Jorgensen, B.; Christiansen, S. E.; Thomsen, M. L. D.; Christensen, C. H. J. Catal. 2007, 251, 332.

(50) Ketchie, W. C.; Fang, Y.-L.; Wong, M. S.; Murayama, M.; Davis, R. J. J. Catal. 2007, 250, 94.

(51) Wheeler, M. C.; Seets, D. C.; Mullins, C. B. J. Chem. Phys. 1996, 105, 1572.

(52) Pollard, J. E. Rev. Sci. Instrum. 1992, 63, 1771.

(53) Wheeler, M. C.; Seets, D. C.; Mullins, C. B. J. Chem. Phys. 1997, 107, 1672.

(54) Kang, H. C.; Mullins, C. B.; Weinberg, W. H. J. Vac. Sci. Technol. A 1990, 8, 2538.

(55) Mullins, C. B.; Weinberg, W. H. J. Chem. Phys. 1990, 92, 3986.

(56) Rettner, C. T.; Mullins, C. B.; Bethune, D. S.; Auerbach, D. J.; Schweizer, E. K.; Weinberg, W. H. J. Vac. Sci. Technol. A 1990, 8, 2699.

(57) Kresse, G.; Hafner, J. Phys. Rev. B 1993, 47, 558.

(58) Kresse, G.; Hafner, J. Phys. Rev. B 1994, 49, 14251.

(59) Kresse, G.; Furthmüller, J. Phys. Rev. B 1996, 54, 11169.

(60) Kresse, G.; Furthmiller, J. Comput. Mater. Sci. 1996, 6, 15.

(61) Blöchl, P. Phys. Rev. B 1994, 50, 17953.

(62) Hohenberg, P.; Kohn, W. Phys. Rev. 1964, 136, B864.

(63) Kohn, W.; Sham, L. J. Phys. Rev. 1965, 140, A1133.

(64) Perdew, J. P.; Burke, K.; Ernzerhof, M. Phys. Rev. Lett. 1996, 77, 3865.

(65) Klimeš, J.; Bowler, D. R.; Michaelides, A. Phys. Rev. B 2011, 83, 195131.

(66) Henkelman, G.; Uberuaga, B. P.; Jónsson, H. J. Chem. Phys. 2000, 113, 9901.

(67) Henkelman, G.; Jónsson, H. J. Chem. Phys. 2000, 113, 9978.

(68) Monkhorst, H. J.; Pack, J. D. Phys. Rev. B 1976, 13, 5188.

(69) Redhead, P. A. Vacuum 1962, 12, 203.

(70) Gong, J.; Flaherty, D. W.; Ojifinni, R. A.; White, J. M.; Mullins, C. B. J. Phys. Chem. C 2008, 112, 5501.

(71) Ehlers, D. H.; Spitzer, A.; Lüth, H. Surf. Sci. 1985, 160, 57.

(72) Burke, D. J.; Wolff, A. J.; Edridge, J. L.; Brown, W. A. J. Chem. Phys. 2008, 128, 104702.

(73) Brown, N. F.; Barteau, M. A. J. Am. Chem. Soc. 1992, 114, 4258.

(74) Kay, B. D.; Lykke, K. R.; Creighton, J. R.; Ward, S. J. J. Chem. Phys. 1989, 91, 5120.

(75) Chang, C.-R.; Yang, X.-F.; Long, B.; Li, J. ACS Catal. 2013, 3, 1693

(76) Min, B. K.; Alemozafar, A. R.; Biener, M. M.; Biener, J.; Friend, C. M. Top. Catal. 2005, 36, 77.

(77) Baker, T. A.; Xu, B.; Liu, X.; Kaxiras, E.; Friend, C. M. J. Phys. Chem. C 2009, 113, 16561.

(78) Baker, T. A.; Liu, X.; Friend, C. M. Phys. Chem. Chem. Phys. 2011, 13, 34.

(79) Min, B. K.; Alemozafar, A. R.; Pinnaduwage, D.; Deng, X.; Friend, C. M. J. Phys. Chem. B 2006, 110, 19833.

(80) Hammer, B.; Nørskov, J. K. Nature 1995, 376, 238.

(81) Tierney, H. L.; Baber, A. E.; Kitchin, J. R.; Sykes, E. C. H. Phys.

Rev. Lett. 2009, 103, 246102.

(82) Quiller, R. G.; Baker, T. A.; Deng, X.; Colling, M. E.; Min, B. K.; Friend, C. M. J. Chem. Phys. 2008, 129, 064702.

(83) Xu, X.; Friend, C. M. Surf. Sci. 1992, 260, 14.

(84) Davis, J. L.; Barteau, M. A. Surf. Sci. 1988, 197, 123.

(85) Syomin, D.; Koel, B. E. Surf. Sci. 2002, 498, 53. 